\title{
Kinetic and thermodynamic investigation into the lead adsorption process from wastewater through magnetic nanocomposite $\mathrm{Fe}_{3} \mathrm{O}_{4} /$ CNT
}

\author{
Fatemeh Elmi $^{1}$ - Tayebe Hosseini ${ }^{1} \cdot$ Mojtaba Shokrolahzade Taleshi $^{1}$ • \\ Farshad Taleshi ${ }^{2}$
}

Received: 13 November 2016/ Accepted: 6 July 2017/Published online: 20 July 2017

(c) Springer International Publishing AG 2017

\begin{abstract}
In this study, magnetic nanocomposite $\mathrm{Fe}_{3} \mathrm{O}_{4} /$ CNT was synthesized through chemical precipitation and was used for uptake of lead from wastewater. The nanocomposite was characterized by XRD, TEM, and FTIR spectroscopy. Batch adsorption experiments were performed to investigate the effects of such various parameters as the $\mathrm{pH}$ of solution, the contact time, and the adsorbent dosage on the adsorption efficiency of $\mathrm{Fe}_{3} \mathrm{O}_{4} /$ CNT. The maximum lead adsorption was observed in $\mathrm{pH}=3,0.16 \mathrm{~g}$ of nanosorbent, the contact time of $40 \mathrm{~min}$, and the temperature of $30^{\circ} \mathrm{C}$. The maximum removal percentage of $\mathrm{Pb}$ ions in optimal conditions by $\mathrm{Fe}_{3} \mathrm{O}_{4} / \mathrm{CNT}$ was $95.5 \%$. Despite the fact that the optimum $\mathrm{pH}=3$, the bath adsorption experiments were performed at $\mathrm{pH}=6 \pm 0.5$. For water with high alkalinity, a problem related to microbiologically induced corrosion may occur. However, high acidic water can accelerate the corrosion rate by increasing the reaction rates or causing physical damage to the pipes. The pseudo-first order and pseudosecond order were used to evaluate the kinetic models and the mechanism of the adsorption. The results indicated that the pseudo-second-order kinetic model resulted in a satisfactory fit for the experimental data $\left(R^{2}=0.99\right)$. The adsorption isotherms were analyzed using Langmuir and Freundlich models. The Freundlich isotherm proved to have a little better correlation compared with that of the Langmuir isotherm. The thermodynamic parameters
\end{abstract}

Fatemeh Elmi

f.elmi@umz.ac.ir

1 Department of Marine Chemistry, Faculty of Marine and Oceanic Sciences, University of Mazandaran, Babolsar, Iran

2 Department of Physics, Faculty of Basic Sciences, Islamic Azad University, Qaem Shahr Branch, Qaem Shahr, Iran indicate that there was a spontaneous endothermic reaction. The process was successfully applied in the treatment of battery wastewater where the presence of organic compounds, copper, lead, zinc, nickel, and cadmium is hardly influenced the removal efficiency of lead ions even after five successive cycles. The results also show that the nanocomposite has a high efficiency of lead removal from wastewater resources.

Keywords $\mathrm{Fe}_{3} \mathrm{O}_{4} / \mathrm{CNT} \cdot$ Magnetic nanocomposite $\cdot$ Lead . Adsorption - Wastewater

\section{Introduction}

Nowadays, the conservation of water resources is of paramount importance, which could be due to the limited number of available resources in the world. Heavy metals such as lead can affect the activity of microorganisms in the soil, which could, in turn, reduce the fertility of the soil. Heavy metals can also prevent the degradation of materials in the soil and disrupt the natural cycles. In the production of thermoplastic tubes, the use of various additives containing lead compounds and the growing use of these materials in plumbing and water distribution systems have increased the concern regarding the release of such metals as lead in drinking water [1]. $\mathrm{Pb}$ is an insidious and cumulative environmental pollutant, which can induce a wide range of physiological, biochemical, and behavioral dysfunctions in living organisms. Excessive amounts of lead can readily accumulate in marine animals like oysters, bivalves, and fishes. Considering its toxicity, non-biocompatibility, and non-biodegradability, it is essential that we remove lead effectively from water and wastewater through appropriate techniques [2]. 
Accordingly, the efficient removal of heavy metals, lead in particular, has been seriously taken into account. Among the new ways to prevent any environmental pollution, the use of biocompatible nanoadsorbents, which have a high potential for the removal of heavy metal cations, has been proposed. Due to their specific structural, mechanical, and electrical properties, carbon nanotubes (CNTs) have attracted the attention of many researchers so far. In recent years, a considerable bulk of research has focused on the improvement of its applications in diverse fields of technology including the arrangement of carbon nanotubes [3]. A good illustration for that is the use of external substances to fill and coat the outer surface of nanotubes [4, 5]. Therefore, several methods such as sol-gel techniques, which are based on CNTs [6], hydrothermal and solvothermal processes [7], and chemical vapor phase deposition $[8,9]$, have been derived for the synthesis of nanocomposites. On the other hand, the very low solubility of CNTs has challenged their use alone. Due to the strong intermolecular van der Waals bonding, CNTs form clusters or closed structures. The cumulative structure could be the reason for their hydrophobic properties and their insolubility in water. The cumulative structure continues in the same vein until compounds such as biomolecules or functionalized polymers are either physically or chemically connected to the surface of the nanotubes [10]. Due to the fact that magnetic nanoparticles of iron (III) oxide, $\mathrm{Fe}_{3} \mathrm{O}_{4}$, are highly abundant and have a specific surface area, they can play an important role, as environmentally friendly materials, in adsorbing pollutants and removing heavy metals. However, magnetic nanoparticles tend to be accumulated in the form of great clusters. This can lead $\mathrm{Fe}_{3} \mathrm{O}_{4}$ nanoparticles to lose both their unique properties and their dispersion due to the anisotropic dipole interactions [10]. One way to prevent their accumulation is to spread them on a specific area of supports such as carbon fibers [11] and graphite [12]. In adsorption processes, the adsorption efficiency is influenced by several parameters such as $\mathrm{pH}$, temperature, contact time, the concentration of pollutants, the particle size of the adsorbent, and the nature of adsorbents and the pollutants. Pre-filtration is a necessary step for the removal of suspended particles and oil, which can reduce the efficiency of the adsorption.

Nanomaterials, such as CNTs and composites of CNTs, have been reported to be promising for the removal of heavy metals and organic pollutants [13]. Research findings suggest that CNTs matrix can accelerate the electron transport and facilitate the adsorption activities of organic and inorganic compounds on the surface of magnetic nanoparticles dispersed. Therefore, compared to common supports such as silica, alumina, and zeolite, CNTs are more efficient. An earlier study by Soldatov et al. demonstrated that polypeptides' nanotubular structures with tunable properties can be a challenging alternative for CNT. Experimental studies also show that L-alanyl-L-valine (AV) and L-valyl-L-alanine (VA) have novel porous materials, which can form channel-like structures [14]. However, DFT calculations show that the HOMO-LUMO band gap of these materials is larger than those of CNTs. Thus, further investigations need to be carried out to design novel materials comparable to those of CNTs [15]. As a result, their great capacity to adsorb a wide range of contaminants, their fast kinetics, and their large specific surface area are among their advantages for water and wastewater treatment. $\mathrm{Fe}_{3} \mathrm{O}_{4} / \mathrm{CNT}$ magnetic nanocomposite can be used for water treatment. They have the ability to remove contaminations such as bacteria and viruses through adsorption. It is worth mentioning that in order to pressurize the flow of CNTs, very little energy is needed. CNTs are suitable in emergency situations because they have a very low tendency for fouling $[16,17]$. $\mathrm{Fe}_{3} \mathrm{O}_{4} / \mathrm{CNT}$ magnetic nanocomposite can also be incorporated into membranes as a nanomesh or used in conjunction with membranes to increase water treatment.

Many adsorbents have been used for the removal of organic compounds and heavy metals from water and wastewaters [18-21]. The results suggest that CNT is an effective support, which can prevent the agglomeration of such metal oxides as $\mathrm{TiO}_{2}$ and $\mathrm{MnO}_{2}$ [20, 21]. Therefore, some of the shortcomings of $\mathrm{Fe}_{3} \mathrm{O}_{4}$ magnetic nanoparticles and CNTs can be enhanced by loading $\mathrm{Fe}_{3} \mathrm{O}_{4}$ magnetic nanoparticles on CNTs as the substrate when they participate in the adsorption process alone. This can increase the efficiency of pollutant adsorption. In this study, through a chemical deposition method, $\mathrm{Fe}_{3} \mathrm{O}_{4}$ nanoparticles were decorated on CNTs. Then, magnetic nanocomposite was used as an adsorbent with high sorption property. Finally, the parameters affecting the adsorption capacity and the removal of lead ions from aqueous solution were studied. The results demonstrated that the magnetic nanocomposite possessed desorption, recyclability, and reusability properties.

\section{Materials and methods}

All the materials used in this study had the highest analytical grade and were purchased from Merck Company. $1000 \mathrm{mg} / \mathrm{L}$ lead stock solution was prepared through dissolving lead salt (II) nitrate in deionized water. The solutions with the desired concentrations were then obtained through diluting the stock solution.

\section{Purification and functionalization of CNTs}

Five grams of CNTs was dissolved in $33 \mathrm{~mL}$ of distilled water, and the solution was placed on a hot plate stirrer at 
the temperature of $50{ }^{\circ} \mathrm{C}$ for $10 \mathrm{~min}$. Next, $25 \mathrm{~mL}$ sulfuric acid and $33 \mathrm{~mL}$ nitric acid were added to it. Then, the sample was placed in the ultrasonic device at the temperature of $50{ }^{\circ} \mathrm{C}$ for $30 \mathrm{~min}$. Again, after this step, the solution was placed on hot plate stirrer at the temperature of $90{ }^{\circ} \mathrm{C}$ for $1 \mathrm{~h}$. $12 \mathrm{~mL}$ of sulfuric acid and $15 \mathrm{~mL}$ of nitric acid were then added to the sample, and ultrasonic was conducted for $10 \mathrm{~min}$. Finally, the resulting solution was placed on a hot plate stirrer at the temperature of $50{ }^{\circ} \mathrm{C}$ for half an hour. After about $1 \mathrm{~h}$, the functionalized CNTs were passed through filter paper and rinsed with distilled water. The desired sample was poured to the certain volume of water so that it could be used for the preparation of nanocomposite [21].

\section{Preparation of $\mathrm{Fe}_{3} \mathrm{O}_{4} / \mathrm{CNT}$ (1:1) using chemical deposition technique}

At this point, $0.5 \mathrm{~g}$ of functionalized CNTs was mixed with $0.43 \mathrm{~g}$ of $\mathrm{FeCl}_{3} \cdot 6 \mathrm{H}_{2} \mathrm{O}$ and $1.17 \mathrm{~g}$ of $\mathrm{FeCl}_{2} \cdot 4 \mathrm{H}_{2} \mathrm{O}$ in $50 \mathrm{~mL}$ of distilled water. It was then stirred until the mixture was well mixed. Then, $25 \mathrm{~mL}$ of ammonium hydroxide was added to the resulted mixture. After $3 \mathrm{~min}$, it was passed through the filter paper and rinsed with distilled water to be neutralized. Then, $\mathrm{Fe}_{3} \mathrm{O}_{4} / \mathrm{CNT}$ nanocomposite with the ratio of $(1: 1)$ was put in an electric furnace at $120^{\circ} \mathrm{C}$ so that it could be dried [22, 23].

\section{Characterization of $\mathrm{Fe}_{3} \mathrm{O}_{4} / \mathrm{CNT}$ magnetic nanocomposite}

The structure of the synthesized $\mathrm{Fe}_{3} \mathrm{O}_{4} / \mathrm{CNT}$ nanocomposite was characterized by powder X-ray diffraction (XRD) through a XRD, Philips, Pw, 1800 diffractometer with $\mathrm{Cu} \mathrm{k} \alpha$ radiation $(\lambda=0.154 \mathrm{~nm})$. Scans were performed over $2 \theta$ from $20^{\circ}$ to $80^{\circ}$. The morphology of the synthesized magnetic nanocomposite was characterized by transmission electron microscope (TEM) analysis using a TEM, Philips, CM10-100 kV microscope. For TEM analysis, the sample was obtained by dipping a holy grid into $\mathrm{Fe}_{3} \mathrm{O}_{4} / \mathrm{CNT}$, which was dispersed in ethanol under ultrasonication and evaporated at room temperature. Fourier transform infrared spectrometer (FTIR, Bruker Tensor 27) was applied to characterize the functional groups in the frequency range of $400-4000 \mathrm{~cm}^{-1}$ and the resolution of $4 \mathrm{~cm}^{-1}$. The sample was prepared in a $\mathrm{KBr}$ pellet.

\section{The adsorption experiment}

The impact of such variables as the adsorbent dosage $(0.04-0.16 \mathrm{~g})$, the $\mathrm{pH}(3 \pm 0.5-6 \pm 0.5)$, the temperature $\left(0-60{ }^{\circ} \mathrm{C}\right)$, and the contact time $(10-40 \mathrm{~min})$ on the adsorption process of $\mathrm{Fe}_{3} \mathrm{O}_{4} / \mathrm{CNT}$ was studied. In total,
$0.1 \mathrm{~g}$ of nanocomposite was stirred in $50 \mathrm{~mL}$ of lead solution at a concentration of $20 \mathrm{ppm}$ at room temperature for $30 \mathrm{~min}$ at $\mathrm{pH}=6 \pm 0.5$. Then, the solution was passed through filter paper (Whatman 42), and the solution under the filter was collected for atomic absorption spectroscopy (novAA 4000P AAS). Similarly, the effect of different factors was performed in accordance with the testing conditions, and the solution under the filter was also collected for atomic absorption spectroscopy.

The equilibrium adsorption capacity $q_{e}(\mathrm{mg} / \mathrm{g})$ of metal ions was obtained using the following equation:

$q_{e}=\frac{\left(C_{0}-C_{e}\right)}{m} V$

In the above equation, $C_{0}$ and $C_{\mathrm{e}}$ are the initial concentrations of metal ions and the equilibrium concentration of metal ions in solution $(\mathrm{mg} / \mathrm{L})$, respectively. $V$ is the volume of the solution (L) and $\mathrm{m}$ is the amount of adsorbent $(\mathrm{g})$. The metal ion removal rate was obtained using Eq. 2.

$\% R=\frac{\left(C_{0}-C_{e}\right)}{C_{0}} \times 100$

where $C_{0}$ and $C_{\mathrm{e}}(\mathrm{mg} / \mathrm{L})$ are the initial and equilibrium concentrations of the $\mathrm{Pb}^{2+}$ in solution, respectively.

\section{The desorption experiment}

$0.1 \mathrm{~g}$ of $\mathrm{Fe}_{3} \mathrm{O}_{4} / \mathrm{CNT}$ nanocomposite (1:1) was stirred on a hot plate stirrer in $50 \mathrm{~mL}$ of lead solution at a concentration of $20 \mathrm{ppm}$ at room temperature and at $\mathrm{pH}=6 \pm 0.5$ for $30 \mathrm{~min}$. Then, the solution was passed through filter paper (Whatman 42), and the solution under the filter was collected for atomic absorption spectroscopy. Then, the nanocomposite on filter paper along with some distilled water was placed on a hot plate to be boiled for about $10 \mathrm{~min}$. The experiment was repeated multiple times in order to obtain the adsorbent recyclability.

\section{Application to real wastewater sample}

The above experimental method was applied for the removal of $\mathrm{Pb}$ ion in real sample with complex media. Before adding the adsorbent, the samples were filtered through a $0.45-\mu \mathrm{m}$ Whatman filter paper and the $\mathrm{pH}$ was adjusted to optimum $\mathrm{pH}$ level. The quantitative measurement of $\mathrm{Pb}^{2+}$ was done by standard addition technique. First, the sample was taken into the flame-AAS and the absorption was measured. After the addition of $100 \mu \mathrm{l}$ of standard solution, the procedure was repeated four times and the absorption was measured. After all the measurement, extrapolation curve was plotted between absorption vs concentration. The extrapolation curve will show the 
amount of $\mathrm{Pb}^{2+}$ present in the sample solution. This procedure was repeated three times, and the removal percentage value of $\mathrm{Pb}$ ion was calculated. The same procedure was applied for the quantitative measurement of copper, zinc, nickel, and cadmium using flame-AAS by standard addition technique.

\section{Results and discussion}

\section{Properties of synthesized $\mathrm{Fe}_{3} \mathrm{O}_{4} / \mathrm{CNT}$ magnetic nanocomposite}

In order to study the type of functional groups on the surface of CNTs, FTIR spectra were taken from the MWCNT before and after functionalization, and $\mathrm{Fe}_{3} \mathrm{O}_{4} /$ CNT. Figure 1 shows FTIR spectra of CNTs before and after the pickling process. Figure 1a shows the non-functionalized CNTs. The peaks observed at the wavelengths of 1460 and $1629 \mathrm{~cm}^{-1}$ are related to $\mathrm{C}=\mathrm{C}$ bond vibration in CNTs. Moreover, the peak at the wavelength of $3443 \mathrm{~cm}^{-1}$ attributes to the presence of hydroxyl group. Figure $1 \mathrm{~b}$ reveals FTIR spectra of functionalized CNTs. With pickling process, the peak intensity of $\mathrm{C}=\mathrm{C}$ dropped, and in contrast, the peaks with the wavelengths of 1032, 1469, 1525 , and $1713 \mathrm{~cm}^{-1}$ were established, which were related to the functional groups $\mathrm{C}-\mathrm{O}, \mathrm{OC}=\mathrm{O}, \mathrm{C}-\mathrm{O}-\mathrm{C}$, and $\mathrm{C}=\mathrm{O}$ in the process of ultrasonic and pickling. The vibration of hydroxyl functional group is also within the wavelength range of $3438 \mathrm{~cm}^{-1}$. The absorption was also observed in the range of 2381 and $2920 \mathrm{~cm}^{-1}$, which were, respectively, related to the vibration band of the carboxyl group and stretching band of $-\mathrm{CH}_{2}-$ methylene group in both spectra. Peaks under the wavelength of $600 \mathrm{~cm}^{-1}$ are related to inorganic catalysts used in the synthesis of CNTs $[23,24]$.

Figure 2 shows FTIR spectrum of $\mathrm{Fe}_{3} \mathrm{O}_{4} / \mathrm{CNT}$. As it can be seen, there is a strong and broad absorption band in the range of $586.3 \mathrm{~cm}^{-1}$. This absorption band is indicative of the vibrational frequency of the bond $\mathrm{Fe}-\mathrm{O}$ of $\mathrm{Fe}_{3} \mathrm{O}_{4}$ nanoparticles, which decorated the CNT surface. The presence of absorption band for hydroxyl functional groups in the wavelength of $3443 \mathrm{~cm}^{-1}$ in magnetic nanocomposite shows that only a fraction of the sites has been occupied by $\mathrm{Fe}_{3} \mathrm{O}_{4}$.

According to FTIR spectroscopy, functional groups on the surface of CNTs are very weak. It shows that the electrostatic interaction may be responsible for the attachment of $\mathrm{Fe}_{3} \mathrm{O}_{4}$ nanoparticles on the outside part of CNTs. This can imply that the unique $\mathrm{sp}^{2}$ structure of the CNTs is not destroyed by acid pretreatment and their electronic properties remain unchanged. Furthermore, in order to study the synthesis and morphology of functionalized CNTs and $\mathrm{Fe}_{3} \mathrm{O}_{4} / \mathrm{CNT}$ more accurately (1:1), TEM images were taken. By comparing images a and b in Fig. 3, it can be seen that $\mathrm{Fe}_{3} \mathrm{O}_{4}$ is separated and the spherical nanoparticles are stuck well on the surface of CNTs.

Figure 4 shows the X-ray diffraction patterns of synthesized magnetic nanocomposites and the synthesized $\mathrm{Fe}_{3} \mathrm{O}_{4}$ nanoparticles. The XRD pattern of the $\mathrm{Fe}_{3} \mathrm{O}_{4}$ nanoparticle is shown in Fig. 4b. The XRD pattern indicates that the magnetite nanoparticles were well crystallized (JCPDS card: No. 89-0688). The major diffraction peaks appear at $18.30^{\circ}, 30.3^{\circ}, 35.7^{\circ}, 43.1^{\circ}, 53.7^{\circ}, 57.3^{\circ}$, $62.6^{\circ}, 72.9^{\circ}$, and $74.6^{\circ}$, which correspond to the (220), (311), (400), (331), (422), (511), (620), and (622) crystal planes of $\mathrm{Fe}_{3} \mathrm{O}_{4}$. As shown in Fig. 4b, the X-ray diffraction of the $\mathrm{Fe}_{3} \mathrm{O}_{4}$ for the highest peak, it is clear that the dimensions of $\mathrm{Fe}_{3} \mathrm{O}_{4}$ nanoparticles are about $10.7 \mathrm{~nm}$. But by observing Fig. $4 \mathrm{a}$, the diffraction pattern of synthesized magnetic nanocomposite, the dimensions of $\mathrm{Fe}_{3} \mathrm{O}_{4}$ nanoparticles dropped to $1.57 \mathrm{~nm}$. The reason for this could be the CNTs matrix, which has limited space for $\mathrm{Fe}_{3} \mathrm{O}_{4}$ nanoparticles. The XRD pattern for the $\mathrm{Fe}_{3} \mathrm{O}_{4} / \mathrm{CNT}$ nanocomposite indicates the dual phases of pure CNT and $\mathrm{Fe}_{3} \mathrm{O}_{4}$, as shown in Fig. 4a. The intensities and peak positions of the broad diffraction peaks at $2 \theta=25^{\circ}, 36^{\circ}$, and $62^{\circ}$ apparently indicated that the CNTs structure was preserved even after being decorated with magnetite [25]. No peaks corresponding to impurities were detected. The peak broadening of the pattern reveals that the as-prepared magnetite nanoparticles are significantly small.

\section{Adsorption process}

\section{The effect of adsorbent dosage}

As it is shown in Fig. 5, the amount of heavy metal adsorption increased by increasing the amount of $\mathrm{Fe}_{3} \mathrm{O}_{4} /$ CNT magnetic nanosorbent and reached $95.5 \%$ in $0.16 \mathrm{~g}$. This could be attributed to the fact that any increase in the amount of nanosorbent could result in an increase in the number of active sites for the adsorption. These results indicate that $\mathrm{Fe}_{3} \mathrm{O}_{4} / \mathrm{CNT}$ magnetic nanocomposite is a suitable adsorbent for removing heavy metals from aqueous solutions. The adsorption condition included the solution $\mathrm{pH}=6 \pm 0.5,20 \mathrm{mg} / \mathrm{L}$ of the initial lead ion concentration, and 30-min contact time at $25 \pm 1{ }^{\circ} \mathrm{C}$.

\section{The effect of temperature and contact time}

As indicated in Fig. 6, the results depict that the highest uptake of $\mathrm{Pb}^{2+}$ ions occurred in $30^{\circ} \mathrm{C}$. However, with the increase in temperature to over $30^{\circ} \mathrm{C}$, the kinetic energy of adsorbed $\mathrm{Pb}^{2+}$ ions was enhanced and the probability of 


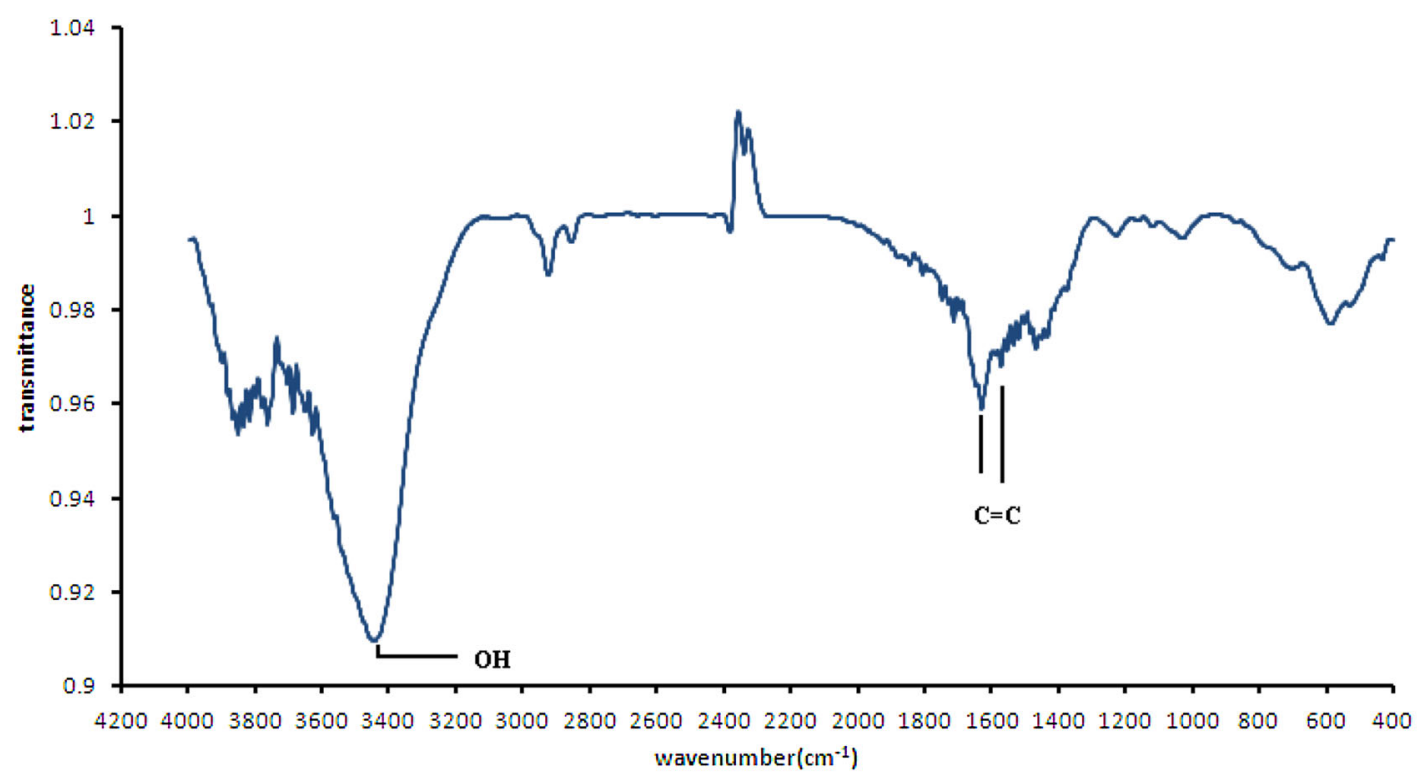

(a)

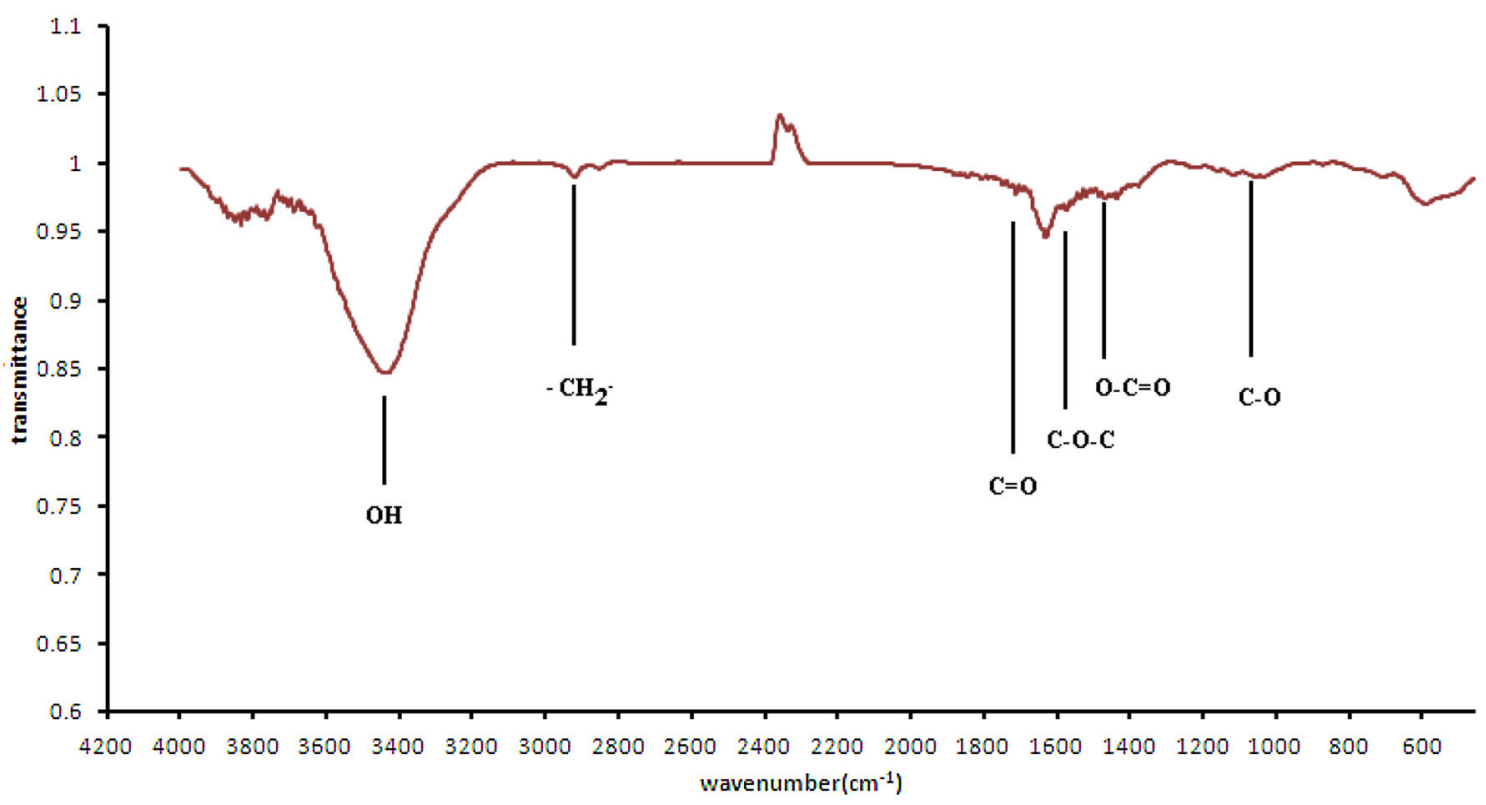

(b)

Fig. 1 FTIR spectrum of MWCNTs a before functionalization and $\mathbf{b}$ after functionalization

the desorption process increased. The impact of contact time on $\mathrm{Pb}^{2+}$ sorption onto the $\mathrm{Fe}_{3} \mathrm{O}_{4} / \mathrm{CNT}$ was also examined. The adsorption condition included the solution $\mathrm{pH}=6 \pm 0.5,20 \mathrm{mg} / \mathrm{L}$ of the initial lead ion concentration, $0.1 \mathrm{~g}$ of $\mathrm{Fe}_{3} \mathrm{O}_{4} / \mathrm{CNT}$, and 30-min contact time. The reaction was carried out with contact time of 10, 20, 30, and $40 \mathrm{~min}$. The results, according to Fig. 7, indicated that the maximum removal percentage was reached at $30 \mathrm{~min}$, after which the reaction achieved equilibrium. The adsorption condition included the solution $\mathrm{pH}=6 \pm 0.5$,
$20 \mathrm{mg} / \mathrm{L}$ of the initial lead ion concentration, $0.1 \mathrm{~g}$ of $\mathrm{Fe}_{3} \mathrm{O}_{4} / \mathrm{CNT}$, and $t=25 \pm 1{ }^{\circ} \mathrm{C}$.

\section{The effect of $\mathrm{pH}$}

The maximum amount of lead ion adsorption occurred in $\mathrm{pH}=3 \pm 0.5$ (Fig. 8). However, in practice, $\mathrm{pH}=3 \pm 0.5$ cannot be used for lead adsorption as it is highly acidic. With the increase in $\mathrm{pH}$, the competition between $\mathrm{H}^{+}$ions in the environment and $\mathrm{Pb}^{+2}$ metal ions adsorbed onto the surface of 


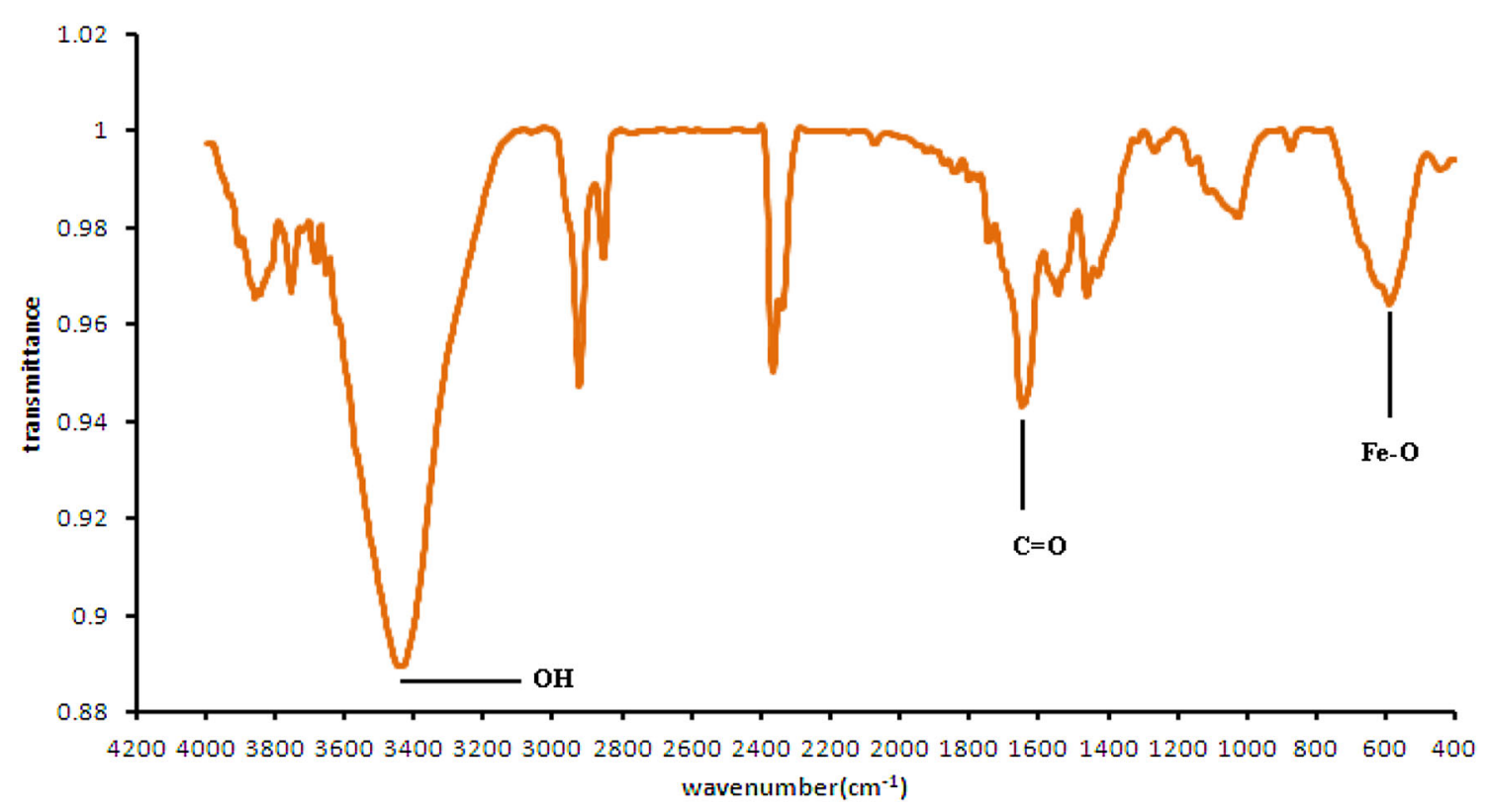

Fig. 2 FTIR spectrum of $\mathrm{Fe}_{3} \mathrm{O}_{4} / \mathrm{CNT}$ magnetic nanocomposite
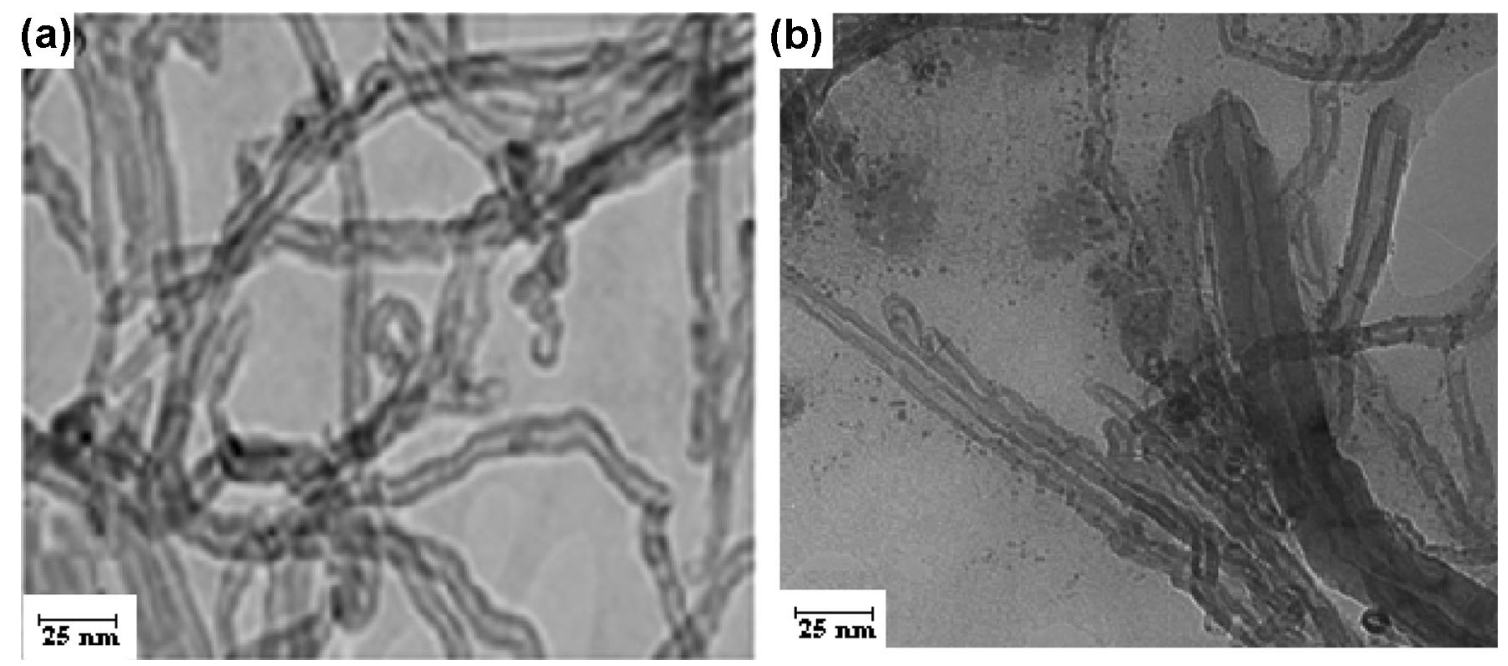

Fig. 3 TEM images of a purified CNTs and $\mathbf{b} \mathrm{Fe}_{3} \mathrm{O}_{4} / \mathrm{CNT}$ magnetic nanocomposite

nanocomposite increases, but the adsorption efficiency decreases, as a result. Also, at alkaline $\mathrm{pH}$ values, lead ions precipitate quickly, and the reduction in the concentration of lead occurs in the form of $\mathrm{Pb}(\mathrm{OH})_{2}$ and $\mathrm{PbOH}^{+}$complexes. Therefore, the lead adsorption by $\mathrm{Fe}_{3} \mathrm{O}_{4} / \mathrm{CNT}$ nanocomposite was studied in $\mathrm{pH}=6 \pm 0.5$. The adsorption condition included $0.1 \mathrm{~g}$ of $\mathrm{Fe}_{3} \mathrm{O}_{4} / \mathrm{CNT}$ magnetic nanocomposite, $20 \mathrm{mg} / \mathrm{L}$ of the initial lead ion concentration, and 30-min contact time at $25 \pm 1{ }^{\circ} \mathrm{C}$.

\section{The desorption experiment}

Desorption studies were conducted to assess the recyclability and the reusability of $\mathrm{Fe}_{3} \mathrm{O}_{4} / \mathrm{CNT}$ magnetic nanocomposite. According to Table 1, it can be mentioned that the lead desorption efficiency was high from the surface of magnetic nanosorbent. After six consecutive cycles, the removal efficiency was still higher than $85 \%$.

\section{Kinetics of adsorption}

The pseudo-first-order and pseudo-second-order kinetic models were used to examine the nature of adsorption mechanism involved during the adsorption process [26]. The pseudo-first-order equation may be stated according to:

$\log \left(q_{e}-q_{t}\right)=\log q_{e}-\frac{K_{1}}{2.303} t$

where $q_{\mathrm{t}}$ is the amount of $\mathrm{Pb}^{2+}$ adsorbed at any time $t(\mathrm{mg} /$ g) and $q_{\mathrm{e}}$ is the amount of $\mathrm{Pb}^{2+}$ adsorbed at equilibrium 

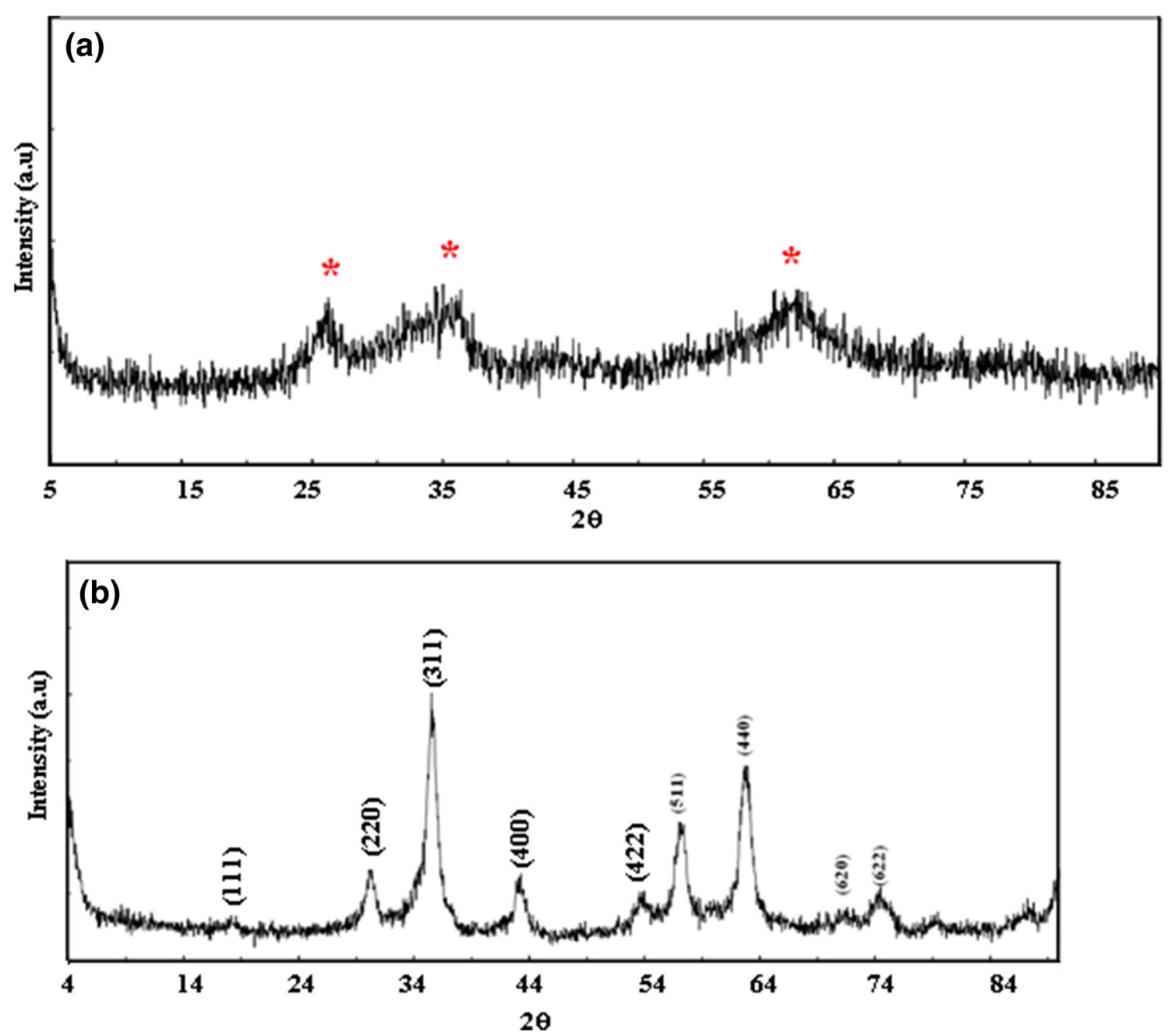

Fig. 4 X-ray diffraction pattern of $\mathbf{a} \mathrm{Fe}_{3} \mathrm{O}_{4} / \mathrm{CNT}$ magnetic nanocomposite and $\mathbf{b} \mathrm{Fe}_{3} \mathrm{O}_{4}$ nanoparticles

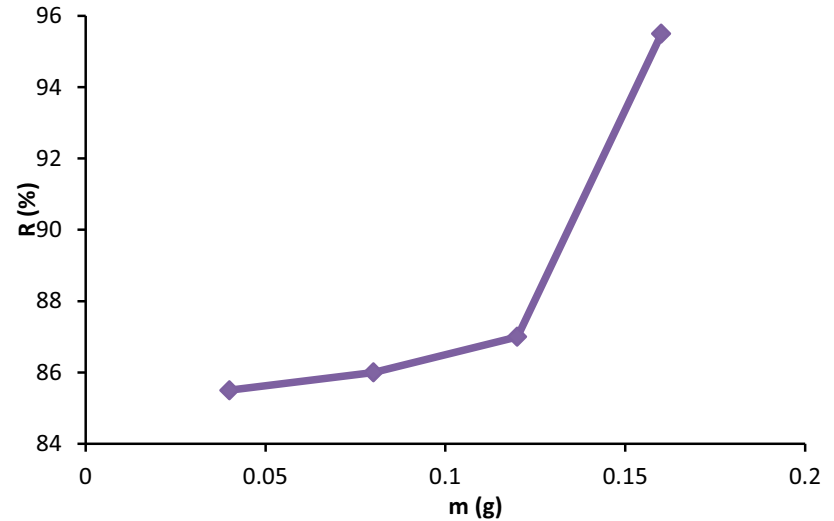

Fig. 5 Effect of the dosage of $\mathrm{Fe}_{3} \mathrm{O}_{4} / \mathrm{CNT}$ nanocomposite on $\mathrm{Pb}^{2+}$ adsorption. Adsorption conditions: solution $\mathrm{pH}=6 \pm 0.5,20 \mathrm{mg} / \mathrm{L}$ initial lead ion concentration, and 30-min contact time at $25 \pm 1{ }^{\circ} \mathrm{C}$

$(\mathrm{mg} / \mathrm{g}) . K_{1}\left(\mathrm{~min}^{-1}\right)$ is the rate constant of the pseudo-firstorder adsorption, which can be calculated from the slope of

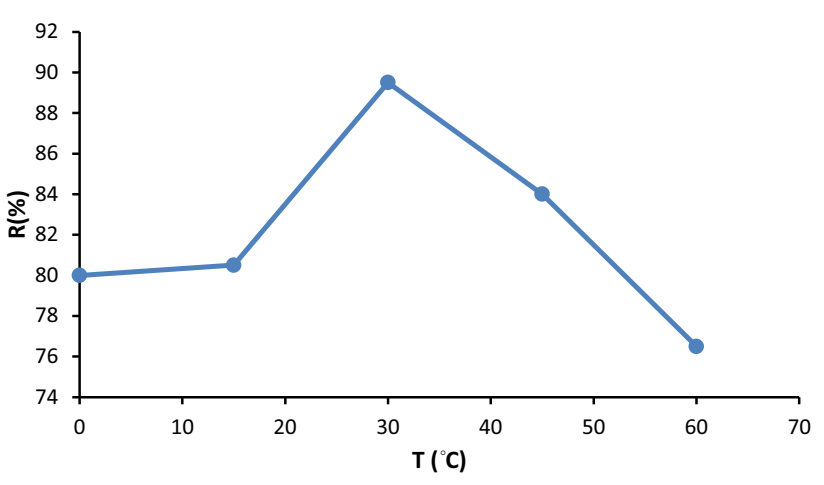

Fig. 6 Effect of temperature on $\mathrm{Pb}^{2+}$ adsorption. Adsorption conditions: solution $\mathrm{pH}=6 \pm 0.5,20 \mathrm{mg} / \mathrm{L}$ initial lead ion concentration, $0.1 \mathrm{~g}$ of $\mathrm{Fe}_{3} \mathrm{O}_{4} / \mathrm{CNT}$, and 30-min contact time

the linear plot of $\log \left(q_{e}-q_{t}\right)$ versus time, $\mathrm{t}$. The linearized form of the pseudo-second-order model is: 
Fig. 7 Effect of contact time on $\mathrm{Pb}^{2+}$ adsorption. Adsorption conditions: solution $\mathrm{pH}=6 \pm 0.5,20 \mathrm{mg} / \mathrm{L}$ initial lead ion concentration, $0.1 \mathrm{~g}$ of $\mathrm{Fe}_{3} \mathrm{O}_{4} / \mathrm{CNT}$, and

temperature $=25 \pm 1{ }^{\circ} \mathrm{C}$

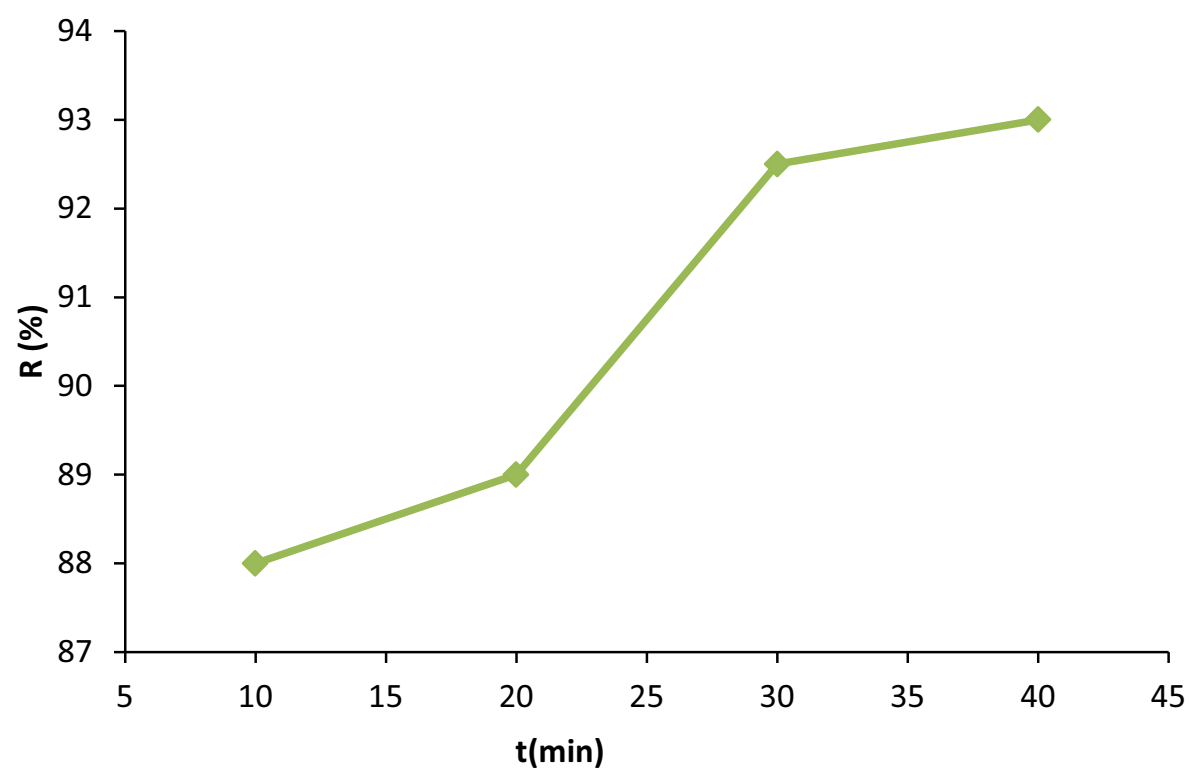

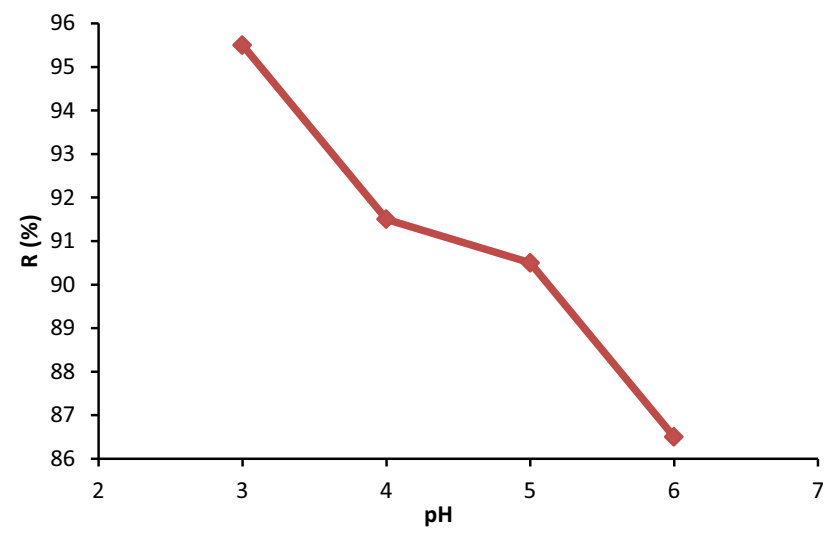

Fig. 8 Effect of the $\mathrm{pH}$ on $\mathrm{Pb}^{2+}$ adsorption. Adsorption conditions: solution $0.1 \mathrm{~g}$ of $\mathrm{Fe}_{3} \mathrm{O}_{4} / \mathrm{CNT}$ magnetic nanocomposite, $20 \mathrm{mg} / \mathrm{L}$ initial lead ion concentration, and 30 -min contact time at $25 \pm 1{ }^{\circ} \mathrm{C}$

Table 1 Evaluation of the recyclability of $\mathrm{Fe}_{3} \mathrm{O}_{4} / \mathrm{CNT}$ magnetic nanocomposite

\begin{tabular}{lll}
\hline Cycle & $\mathrm{Ct}(\mathrm{mg} / \mathrm{l})$ & Removal percentage $(\%)$ \\
\hline First & $1.2 \pm 0.04$ & 94 \\
Second & $1.3 \pm 0.09$ & 93.5 \\
Third & $1.5 \pm 0.05$ & 92.5 \\
Fourth & $2.4 \pm 0.10$ & 88 \\
Fifth & $2.6 \pm 0.11$ & 87 \\
Sixth & $2.9 \pm 0.05$ & 85.5 \\
\hline
\end{tabular}

$\frac{t}{q_{t}}=\frac{1}{K_{2} q_{e}^{2}}+\frac{1}{q_{e}} t$
Table 2 Pseudo-first order and pseudo-second order kinetic parameters for $\mathrm{Fe}_{3} \mathrm{O}_{4} / \mathrm{CNT}$ magnetic nanocomposite

\begin{tabular}{lllll}
\hline Kinetic model & $R^{2}$ & $\mathrm{q}_{\mathrm{e}, \mathrm{cal}}$ & $\mathrm{q}_{\mathrm{e}, \exp }$ & $K$ \\
\hline Pseudo-first order & 0.8666 & 1.06 & 9.30 & 0.087 \\
Pseudo-second order & 0.9994 & 9.50 & 9.34 & 0.26 \\
\hline
\end{tabular}

where $q_{\mathrm{e}}$ is the amount of $\mathrm{Pb}^{2+}$ adsorbed on the $\mathrm{Fe}_{3} \mathrm{O}_{4} /$ CNT nanocomposite at equilibrium $(\mathrm{mg} / \mathrm{g})$ and $\mathrm{qt}$ is the amount of $\mathrm{Pb}^{2+}$ adsorbed on the $\mathrm{Fe}_{3} \mathrm{O}_{4} / \mathrm{CNT}$ nanocomposite at any time, $\mathrm{t}(\mathrm{mg} / \mathrm{g}) . K_{2}(\mathrm{~g} / \mathrm{mg} \mathrm{min})$ is the rate constant of the pseudo-second-order adsorption, which can be calculated from the intercept of the plot of $t / q_{\mathrm{t}}$ against $t$.

The correlation coefficients $\left(R^{2}\right)$ for the pseudo-firstorder and pseudo-second-order were 0.8666 and 0.9994 , respectively (Table 2). For the pseudo-second-order, the theoretical value of $q_{\mathrm{e}}$ agrees very well with the experimental value. Therefore, it can be concluded that pseudosecond-order model might well be used to express the adsorption kinetics. This model is based on the assumption that the rate-limiting step may be chemisorptions, which involves the valence forces through sharing or the exchange of electrons between the $\mathrm{Fe}_{3} \mathrm{O}_{4} / \mathrm{CNT}$ and the lead ions [27]. In chemisorption, the $\mathrm{Pb}^{2+}$ ions can adhere to the $\mathrm{Fe}_{3} \mathrm{O}_{4} / \mathrm{CNT}$ surface by forming chemical bonds and tend to find sites, which can maximize the coordination [28].

\section{The adsorption isotherms}

The Langmuir model supposes that the adsorption happens on a monolayer surface at the specific sites of the 
adsorbent. A well-known linear form of Langmuir model is given by:

$\frac{C_{e}}{q_{e}}=\frac{C_{e}}{q_{\max }}+\frac{1}{q_{\max } K_{L}}$

where $q_{\max }$ is the maximum amount of the adsorption capacity $(\mathrm{mg} / \mathrm{g})$ of $\mathrm{Pb}^{2+}$, which is adsorbed to form a complete monolayer covered on the surface at the equilibrium, $C_{\mathrm{e}}$ is the equilibrium concentration of lead $(\mathrm{mg} / \mathrm{L})$, $q_{\mathrm{e}}$ is the amount of lead adsorbed at the equilibrium $(\mathrm{mg} / \mathrm{g})$, and $K_{\mathrm{L}}$ is the Langmuir constant $(\mathrm{L} / \mathrm{mg})$, which is related to the surface affinity for lead. The crucial characteristics of the Langmuir isotherm may be expressed in terms of the equilibrium parameter $R_{\mathrm{L}}$, which is known as the separation factor or the equilibrium parameter.

$R_{L}=\frac{1}{1+K_{L} C_{0}}$

The $R_{\mathrm{L}}$ values indicate that the type of adsorption is either unfavorable $\left(R_{\mathrm{L}}>1\right)$, linear $\left(R_{\mathrm{L}}=1\right)$, favorable $\left(0<R_{\mathrm{L}}<1\right)$, or irreversible $\left(R_{\mathrm{L}}=0\right)$.

The Freundlich isotherm model describes the adsorption on the heterogeneous surfaces with the interaction between the adsorbed molecules and is not limited to the formation of a monolayer. This model presumes that as the adsorbate concentration increases, its concentration on the surface of adsorbent also increases, and correspondingly, the sorption energy exponentially decreases on the completion of the sorption centers of the adsorbent. The well-known expression for the Freundlich model is given as

$\log q_{e}=\log K_{F}+\left(\frac{1}{n_{F}}\right) \log C_{e}$

where $q_{\mathrm{e}}$ is the amount of $\mathrm{Pb}^{2+}$ adsorbed on the $\mathrm{Fe}_{3} \mathrm{O}_{4} /$ CNT nanocomposite at equilibrium $(\mathrm{mg} / \mathrm{g})$ and $K_{\mathrm{F}}$ and $n_{\mathrm{F}}$ are the Freundlich constants and the intensity of adsorption, respectively. While the constant $K_{\mathrm{F}}$ approximately gives adsorption capacity, $1 / n_{\mathrm{F}}$ is a function of the adsorption strength in the adsorption process. The fitting plots of Langmuir adsorption and the Freundlich adsorption of lead onto magnetic nanocomposites are shown in Figs. 9 and 10 , respectively. From the results, it can be concluded that most $R^{2}>0.9$ for both the Freundlich and Langmuir models, suggesting that both models closely fitted the experimental data. However, the regression results indicate that the Freundlich isotherm fitted the experimental results a little better than the Langmuir isotherm, as given in Table 3 . The $K_{\mathrm{F}}$ and n can increase with any increase in temperature. This can imply that the adsorption capacity of lead ions onto $\mathrm{Fe}_{3} \mathrm{O}_{4} / \mathrm{CNT}$ magnetic nanocomposite can increase, and the degree of heterogeneity of $\mathrm{Fe}_{3} \mathrm{O}_{4} / \mathrm{CNT}$ surface can decrease with the increase in temperature. All values of $n$ are greater than one, suggesting that the

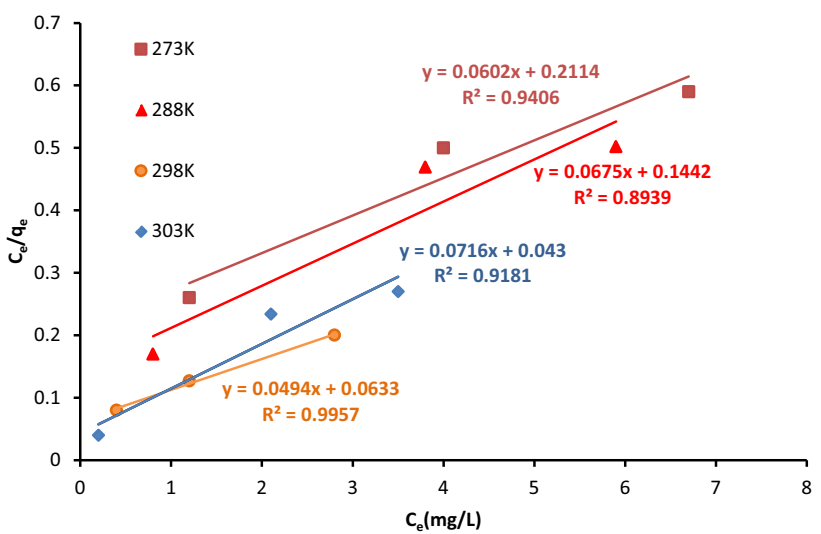

Fig. 9 The Langmuir adsorption plots for lead adsorption onto $\mathrm{Fe}_{3} \mathrm{O}_{4} / \mathrm{CNT}$. Adsorption conditions: solution $\mathrm{pH}=6 \pm 0.5,20 \mathrm{mg} / \mathrm{L}$ initial lead ion concentration, $0.1 \mathrm{~g}$ of $\mathrm{Fe}_{3} \mathrm{O}_{4} / \mathrm{CNT}$, and 30-min contact time

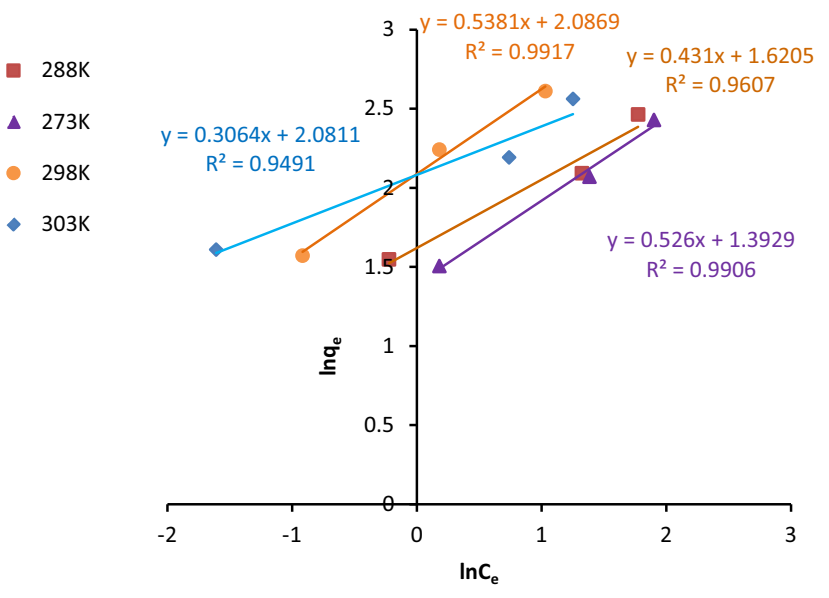

Fig. 10 The Freundlich adsorption plots for lead adsorption onto $\mathrm{Fe}_{3} \mathrm{O}_{4} / \mathrm{CNT}$. Adsorption conditions: solution $\mathrm{pH}=6 \pm 0.5,20 \mathrm{mg} / \mathrm{L}$ initial lead ion concentration, $0.1 \mathrm{~g}$ of $\mathrm{Fe}_{3} \mathrm{O}_{4} / \mathrm{CNT}$, and 30-min contact time

adsorption is a physical process [29]. The RL values indicated that the Langmuir isotherm is also favorable $(0<\mathrm{RL}<1)$.

The qmax from Langmuir isotherm of $\mathrm{Fe}_{3} \mathrm{O}_{4} / \mathrm{CNT}$ magnetic nanocomposite for the removal of lead ions was compared with those of other adsorbents. It is clear from Table 4 that the adsorption capacity of $\mathrm{Fe}_{3} \mathrm{O}_{4} / \mathrm{CNT}$ magnetic nanocomposite was comparable to the previously reported capacities [18, 30-34].

\section{Thermodynamic evaluation of adsorption process}

In order to determine the mechanism of adsorption process, thermodynamic parameters were calculated. Such thermodynamic factors as Gibbs free energy change $\left(\Delta G^{\circ}\right)$ $(\mathrm{kJ} / \mathrm{mol})$, enthalpy change $\left(\Delta H^{\circ}\right)(\mathrm{kJ} / \mathrm{mol})$, and entropy 
Table 3 Langmuir and Freundlich isotherm constants for the lead adsorption onto $\mathrm{Fe}_{3} \mathrm{O}_{4} / \mathrm{CNT}$ at different temperatures

\begin{tabular}{|c|c|c|c|c|c|c|c|}
\hline \multirow[t]{2}{*}{ Temperature (K) } & \multicolumn{3}{|c|}{ Freundlich isotherm } & \multicolumn{4}{|c|}{ Langmuir isotherm } \\
\hline & $1 / \mathrm{n}$ & $K_{\mathrm{F}}(\mathrm{mg} / \mathrm{g})(\mathrm{L} / \mathrm{mg})^{1 / \mathrm{n}}$ & $R^{2}$ & $q_{\max }(\mathrm{mg} / \mathrm{g})$ & $K_{\mathrm{L}}(\mathrm{L} / \mathrm{mg})$ & $R_{\mathrm{L}}$ & $R^{2}$ \\
\hline 273 & 0.526 & 4.02 & 0.9906 & 16.61 & 0.284 & 0.149 & 0.9406 \\
\hline 288 & 0.431 & 5.05 & 0.9607 & 14.81 & 0.468 & 0.096 & 0.8939 \\
\hline 298 & 0.491 & 7.95 & 0.9859 & 21.55 & 0.69 & 0.067 & 0.9981 \\
\hline 303 & 0.307 & 8.01 & 0.9491 & 13.96 & 1.66 & 0.029 & 0.9181 \\
\hline
\end{tabular}

Table 4 Comparing the adsorption capacity of $\mathrm{Fe}_{3} \mathrm{O}_{4} / \mathrm{CNT}$ with the adsorption capacity of different adsorbents for lead ions

\begin{tabular}{lll}
\hline Sorbent samples & Adsorption capacity $q_{\mathrm{m}}$ & References \\
\hline Zeolite $/ \mathrm{Fe}_{3} \mathrm{O}_{4}$ & 50.0 & {$[30]$} \\
Zeolite $/ \mathrm{CuO}$ & 45.45 & {$[30]$} \\
$\mathrm{MWCNTs} / \mathrm{Fe}_{3} \mathrm{O}_{4}$ & 22.04 & {$[31]$} \\
$\mathrm{Fe}_{3} \mathrm{O}_{4}$ nanospheres & $9-19$ & {$[32]$} \\
$\mathrm{MWCNTs}^{\text {Acidified MWCNTs }}$ & 15.9 & {$[33]$} \\
$\mathrm{ZnO} / \mathrm{talc}$ & 17.44 & {$[34]$} \\
$\mathrm{Fe}_{3} \mathrm{O}_{4} / \mathrm{CNT}$ & 48.3 & {$[18]$} \\
\hline
\end{tabular}

change $\left(\Delta S^{\circ}\right)(\mathrm{J} / \mathrm{mol} \mathrm{K})$ were calculated using the following equations and are given in Table 4.

$K_{c}=\frac{C_{\mathrm{Ae}}}{C_{e}}$

$\Delta G^{\circ}=-R T \ln K_{c}$

$\ln k_{c}=\frac{\Delta S^{\circ}}{R}-\frac{\Delta H^{\circ}}{R T}$

where $C_{\mathrm{Ae}}$ is the amount of lead ions adsorbed per unit mass of $\mathrm{Fe}_{3} \mathrm{O}_{4} / \mathrm{CNT}$ nanocomposite $(\mathrm{mg} / \mathrm{g}), C_{\mathrm{e}}$ is the concentration of $\mathrm{Pb}^{2+}$ in liquid phase $(\mathrm{mg} / \mathrm{L}), K_{\mathrm{c}}$ is the equilibrium constant, $R$ is general gas constant, and $T$ is the temperature in Kelvin.

Thermodynamic parameters can be calculated from different constants [35]. From the slope and the intercept of the linear plot $\ln K_{\mathrm{c}}$ versus $1 / \mathrm{T}, \Delta H^{\circ}$ and $\Delta S^{\circ}$ were calculated (Table 4). As Fig. 11 shows, Van't Hoff equation does not fully coincide with the actual adsorption process. From the variations of the $K_{\mathrm{c}}$, which was determined using the method from Milonjić [36], $K_{\mathrm{c}}$ can be derived from the $K_{\mathrm{F}}$ and $K_{\mathrm{L}}$. Based on the data obtained (Table 4), it can be claimed that $\Delta G^{\circ}<0$ indicates that the process is spontaneous while the positive values of $\Delta H^{\circ}$ show that the process of lead adsorption is endothermic. The attraction of the $\mathrm{Fe}_{3} \mathrm{O}_{4} / \mathrm{CNT}$ for $\mathrm{Pb}^{2+}$ ions is reflected through the positive values of entropy $\left(\Delta \mathrm{S}^{\circ}\right)$. The small positive values of $\Delta \mathrm{H}^{\circ}$ indicate that the adsorption of $\mathrm{Pb}^{2+}$ onto $\mathrm{Fe}_{3} \mathrm{O}_{4} /$ CNT the bonding between adsorbate and adsorbent is weak. In addition, the $\Delta G^{\circ}$ for physisorption is less than that of the chemisorption. The former is in the range of -20 to $0 \mathrm{~kJ} / \mathrm{mol}$, and the latter is between -80 and $-400 \mathrm{~kJ} / \mathrm{mol}$ [37] (Table 5).

\section{Real wastewater sample treatment}

Reusability of the adsorbent is vital in economic growth because disposal of adsorbent loaded with heavy metals makes environmental problems. Therefore, reusability must create a small amount of metal concentrate suitable for metal recovery without detrimental effect on the capacity of adsorbent. In this study, to gain the reusability of the $\mathrm{Fe}_{3} \mathrm{O}_{4} / \mathrm{CNT}$ for battery wastewater and to evaluate practical application of magnetic nanocomposite, the adsorption followed by desorption cycle was repeated five times with the same amount of adsorbent. The relative high COD content $(709 \mathrm{mg} / \mathrm{l})$ of the wastewater is indicative of the presence of organic compounds in the wastewater. For the first cycle, the initial COD of $709 \mathrm{mg} / \mathrm{l}$ decreased to $680 \mathrm{mg} / \mathrm{l}$, resulting in a removal efficiency of about $4 \%$. However, the removal efficiency of $\mathrm{Pb}^{2+}$ ions is higher than $80 \%$ after five successive cycles. The obtained results confirm that the presence of organic compounds does not have significant effect on the removal percentage of $\mathrm{Pb}^{2+}$ ions. Initial ion concentration in battery wastewater was carried out for copper: $9.8 \pm 0.26 \mathrm{mg} / \mathrm{L}$, lead: $5.1 \pm 0.37 \mathrm{mg} / \mathrm{L}, \quad$ zinc: $\quad 11.7 \pm 0.19 \mathrm{mg} / \mathrm{L}, \quad$ nickel: $2.3 \pm 0.23 \mathrm{mg} / \mathrm{L}$, and cadmium: $0.35 \pm 0.08 \mathrm{mg} / \mathrm{L}$. The magnetic nanocomposite showed high recovery with approximately stable efficiency (Fig. 12). This indicates that the removal efficiencies of $\mathrm{Pb}(\mathrm{II})$ are hardly influenced by the real wastewater matrix. The results of this study show the high efficiency and capability of $\mathrm{Fe}_{3} \mathrm{O}_{4} / \mathrm{CNT}$ as a potential adsorbent for uptake of $\mathrm{Pb}^{2+}$ ions from wastewater resources.

\section{Conclusions}

$\mathrm{Fe}_{3} \mathrm{O}_{4} / \mathrm{CNT}$ magnetic nanocomposite can act as an efficient adsorbent for the removal of heavy metal lead. The experimental data indicate that the adsorption capacity depends on variables such as time, temperature, the 
Fig. 11 Van't Hoff plot, $\ln K_{\mathrm{c}}$ versus $1 / \mathrm{T}$ for $\mathrm{Pb}^{2+}$ sorption on $\mathrm{Fe}_{3} \mathrm{O}_{4} / \mathrm{CNT}$ magnetic nanosorbent. Adsorption conditions: $\mathrm{Pb}^{2+}$ initial concentrations at $20 \mathrm{mg} / \mathrm{L}$, adsorbent dosage at $0.1 \mathrm{~g}$, 30 -min contact time, and $\mathrm{pH}=6 \pm 0.5$ solution

Table 5 Thermodynamic parameters of lead ion adsorption onto $\mathrm{Fe}_{3} \mathrm{O}_{4} / \mathrm{CNT}$ magnetic nanocomposite

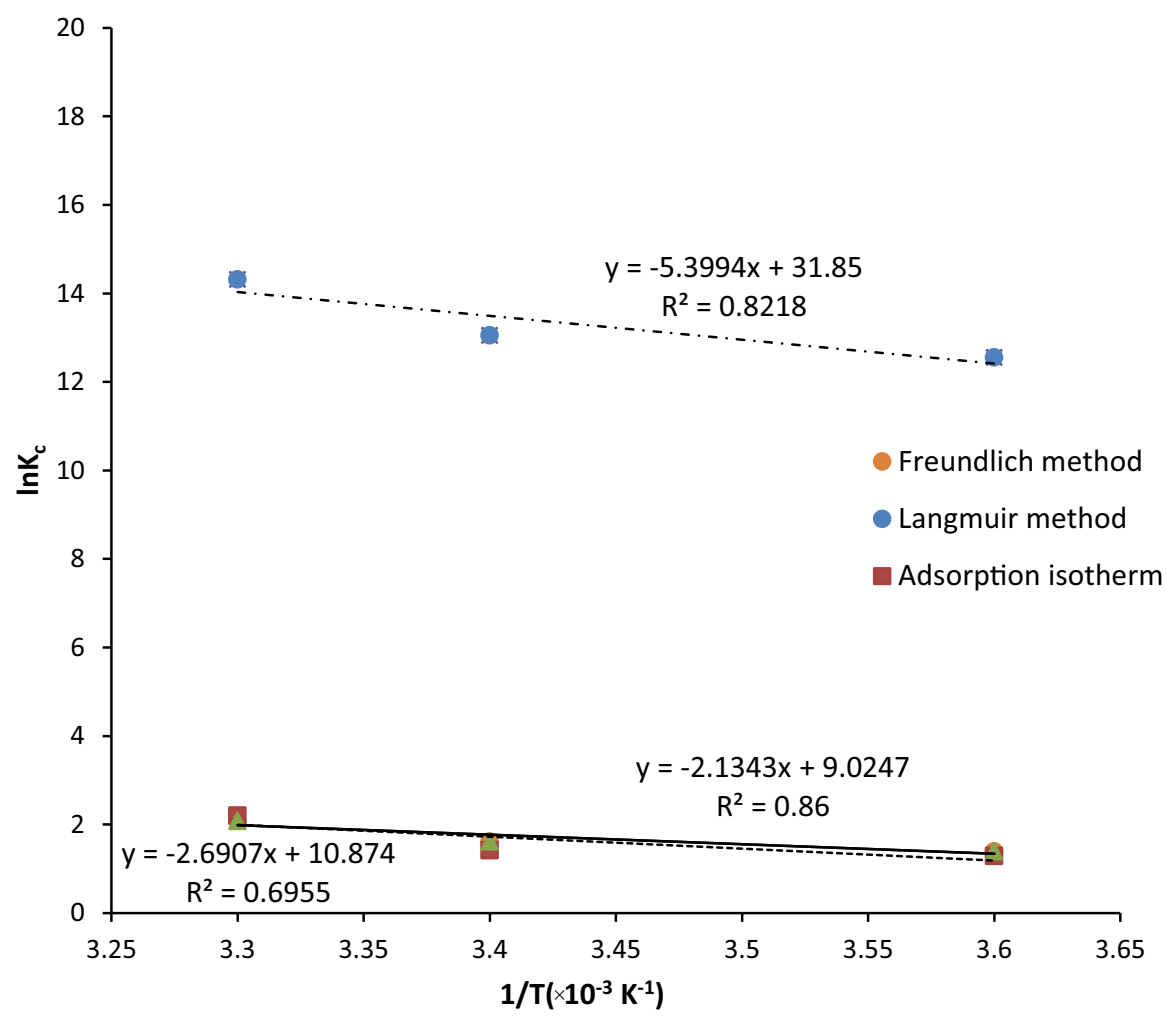

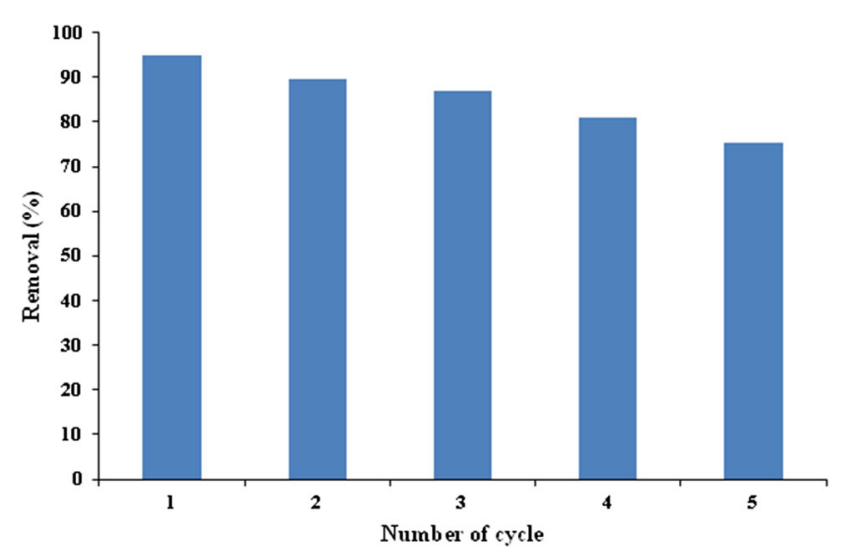

Fig. 12 Removal efficiency of $\mathrm{Pb}^{2+}$ from battery wastewater in different cycles by $\mathrm{Fe}_{3} \mathrm{O}_{4} / \mathrm{CNT}$ magnetic nanocomposite adsorbent dosage, and $\mathrm{pH}$. The maximum adsorption was observed in $\mathrm{pH}=3 \pm 0.5$, the concentration of $0.16 \mathrm{~g}$ of $\mathrm{Fe}_{3} \mathrm{O}_{4} / \mathrm{CNT}$, and the contact time of $40 \mathrm{~min}$ at $30^{\circ} \mathrm{C}$. The highest percentage of lead removal in optimum condition was $95.5 \%$. In practice, at very low, $\mathrm{pH}$ does not work because the speed of water and sewage pipe corrosion process increases. In addition, at alkaline $\mathrm{pH}$, it is possible to have the deposition of lead in the form of hydroxide complexes of $\mathrm{Pb}(\mathrm{OH})_{2}$ and $\mathrm{PbOH}^{+}$. Also, for high alkalinity water, a problem associated with MIC may occur. Therefore, the process of adsorption in this study was evaluated at $\mathrm{pH}=6 \pm 0.5$. The kinetics of adsorption followed the pseudo-second-order model. The thermodynamic evaluation demonstrates that the lead adsorption process is a spontaneous and 
endothermic reaction. The process was successfully applied in the treatment of battery wastewater where the presence of organic compounds, copper, lead, zinc, nickel, and cadmium is hardly influenced the removal efficiency of lead ions even after five successive cycles. Based on the results, it can be seen that the synthesized $\mathrm{Fe}_{3} \mathrm{O}_{4} / \mathrm{CNT}$ magnetic nanocomposite is highly efficient as a recyclable tool in the efficient removal of heavy metals from water and wastewater resources.

Acknowledgement This work was supported by Department of Marine Chemistry, Faculty of Marine \& Oceanic Sciences, University of Mazandaran, Babolsar, Iran.

\section{References}

1. Massoudinejad MR, Saeadi M, Hosseini R, Aghayani E (2015) Evaluation of the probability of water pollution due to lead leaching of thermoplastic pipes in drinking water distribution networks. J Saf Promot Inj Prev 3(2):77-82

2. Ghasemi M, Naushad M, Ghasemi N, Khosravifard Y (2014) Adsorption of $\mathrm{Pb}(\mathrm{II})$ from aqueous solution using new adsorbents prepared from agricultural waste: adsorption isotherm and kinetic studies. J Ind Eng Chem 20:2193-2199

3. Dai H (2002) Carbon nanotubes: synthesis, integration and properties. Acc Chem Res 35(12):1035-1044

4. Das R, Hamid SBA, Ali ME, Ismail AF, Annuar MSM, Ramakrishna S (2014) Multifunctional carbon nanotubes in water treatment: the present, past and future. Desalination 345:160-179

5. Li Z, Willms C, Roy S, Bowman RS (2003) Desorption of hexadecyltrimethyl ammonium from charged mineral surfaces. Environ Geosci 10(1):37-45

6. Yacamán MJ, Rendón L, Arenas J, Puche MCS (1996) Maya blue paint: an ancient nanostructured material. Science 273(5272):223-225

7. Liu W (2005) Catalyst technology development from macro, micro-down to nano-scale. China Part 3(6):383-394

8. Cheung CL, Kurtz A, Park H, Lieber MC (2002) Diametercontrolled synthesis of carbon nanotubes. Phys Chem B 106(10):2429-2433

9. Kobayashi Y, Nakashima H, Takagi D, Homma Y (2004) CVD growth of single-walled carbon nanotubes using size-controlled nanoparticle catalyst. Thin Solid Films 464-465:286-289

10. Sahika B, Ismail I (2003) Adsorption of $\mathrm{Pb}(\mathrm{II})$ ions from aqueous solutions by carbon nanotubes oxidized different methods. J Ind Eng Chem 19(6):2064-2071

11. Qian D, Wagner GJ, Liu WK, Yu MF, Ruoff RS (2002) Mechanics of carbon nanotubes. Appl Mech Rev 55(6):495-533

12. Jong LS, Koo BH, Eun YJ, Hoon HJ (2002) Nanotechnology: synthesis, structures and properties 'a review of current carbon nanomaterials and other nanoparticle technologies'. Diam Relat Mater 11:914

13. Saleh TA, Gupta VK (2016) Nanomaterials and polymer membranes: synthesis, characterization, and application. Elsevier, New York. ISBN 13: 978-0128047033

14. Soldatov DV, Moudrakovski IL, Ripmeester JA (2004) Dipeptides as microporous materials. Angew Chem 43:6308
15. Praveena G, Kolandaivel P, Santhanamoorthi N, Renugopalakrishnan V, Ramakrishna S (2007) Looking beyond carbon nanotubes: polypeptide nanotubes as alternatives? J Nanosci Nanotechnol 7(7):2253

16. Ray CH, Jain R (2014) Low cost emergency water purification technologies: integrated water security series. Elsevier, New York. ISBN 978-0-12-411465-4

17. Saleh TA, Gupta VK, Al-Saadi AA (2013) Adsorption of lead ions from aqueous solution using porous carbon derived from rubber tires: experimental and computational study. J Colloid Interface Sci 396:264-269

18. Sani HA, Ahmad MB, Saleh TA (2016) Synthesis of zinc oxide/talc nanocomposite for enhanced lead adsorption from aqueous solutions. RSC Adv 6:108819-108827

19. Saleh TA, Gupta VK (2012) Column with CNT/magnesium oxide composite for lead (II) removal from water. Environ Sci Pollut Res 19:1224-1228

20. Saleh TA, Gupta VK (2012) Photo-catalyzed degradation of hazardous dye methyl orange by use of a composite catalyst consisting of multi-walled carbon nanotubes and titanium dioxide. J Colloid Interface Sci 371:101-106

21. Vanetsev AS, Ivanov VK, Tretyakov YD (2002) Microwave synthesis of lithium, copper, cobalt, and nickel ferrites. Dokl Chem 387(4):332-334

22. Akbarzadeh A, Samiei M, Davaran S (2012) Magnetic nanoparticles: preparation, physical properties, and applications in biomedicine. Nanoscale Res Lett 7(1):144

23. Ghandoor HE, Zidan HM, Khalil MMH, Ismail MIM (2012) Synthesis and some physical properties of magnetite $\mathrm{Fe}_{3} \mathrm{O}_{4}$ nanoparticles. Int J Electrochem Sci 7:5734-5745

24. Kim DK, Zhang Y, Voit W, Rao KV, Muhammed M (2001) Synthesis and characterization of surfactant-coated superparamagnetic monodispersed iron oxide nanoparticles. J Magn Magn Mater 225:30-36

25. Maity D, Agrawal DC (2007) Synthesis of iron oxide nanoparticles under oxidizing environment and their stabilization in aqueous and nonaqueous media. J Magn Magn Mater 308:46-55

26. Ho YS, Mckay G (1999) Pseudo-second order model for sorption processes. Process Biochem 34(5):451-465

27. Lin K, Pan J, Chen Y, Cheng R, Xu X (2009) Study the adsorption of phenol from aqueous solution on hydroxyapatite nanopowders. J Hazard Mater 161:231-240

28. Atkins PW (2014) Physical chemistry, 10th edn. Oxford University Press, Oxford

29. Birch F (1986) Equation of state and thermodynamic parameters of $\mathrm{NaCl}$ to $300 \mathrm{Kbar}$ in the high temperature domain. J Geophys Res Solid Earth 91(5):4949-4954

30. Alswat AA, Ahmad MB, Saleh TA (2016) Zeolite modified with copper oxide and iron oxide for lead and arsenic adsorption from aqueous solutions. J water Supply Res Technol 65(6):465-479

31. Ji LQ, Zhou LC, Bai X, Shao YM, Zhao GH, Qu YZ, Wang C, Li YF (2012) Facile synthesis of multiwall carbon nanotubes/iron oxides for removal of tetrabromobisphenol $\mathrm{A}$ and $\mathrm{Pb}(\mathrm{II})$. J Mater Chem 22:15853-15862

32. Kumari M, Pittman CU, Mohan D (2015) Heavy metals [chromium (VI) and lead (II)] removal from water using mesoporous magnetite $\left(\mathrm{Fe}_{3} \mathrm{O}_{4}\right)$ nanospheres. $\mathrm{J}$ Colloid Interface Sci 442:120-132

33. Ren XM, Shao DD, Zhao GX, Sheng GD, Hu J, Yang ST, Wang XK (2011) Plasma induced multiwalled carbon nanotube grafted 
with 2-vinylpyridine for preconcentration of $\mathrm{Pb}$ (II) from aqueous solutions. Plasma Process Polym 8:589-598

34. Li X, Li Z, Xia Q, Xi HX (2006) Effects of textural properties and surface oxygen content of activated carbons on desorption of activation energy of water. Adsorpt Sci Technol V24:363-369

35. Tran HN, You SJ, Chao HP (2016) Thermodynamic parameters of cadmium adsorption onto orange peel calculated from various methods: a comparison study journal. J Environ Chem Eng 4:2671-2682

36. Milonjić SK (2007) A consideration of the correct calculation of thermodynamic parameters of adsorption. J Serb Chem Soc 72(12):1363-1367

37. Jaycock MJ, Parfitt GD (1981) Chemistry of interfaces. Ellis Horwood, Chichester 